\title{
CIVIC EDUCATION DI NEGARA KOREA SELATAN DAN INGGRIS
}

\author{
Fatikha Fauziah \\ Universitas Negeri Yogyakarta \\ Fauziahh20@uny.ac.id
}

\begin{abstract}
Abstrak
Pendidikan diyakini berperan penting dalam memajukan peradaban bangsa. Hampir setiap negara menanamkan kewarganegaraan melalui pendidikan dengan cara yang berbeda-beda. Perbedaan ini dilatarbelakangi oleh perkembangan sejarah, ekonomi, identitas nasional, dan budaya setiap negara. Artikel ini bertujuan untuk menganalisis pendidikan kewarganegaraan di Korea Selatan dan Inggris dengan menggali atribut yang melatarbelakanginya. Kedua negara dipilih karena memiliki kesebandingan yakni maju dalam bidang industry. Hasil telaah menunjukkan bahwa terdapat perbedaan kurikulum pendidikan kewarganegaraan di kedua negara. Inti dari pendidikan kewarganegaraan (civic virtue) di Korea Selatan berasal dari budaya dan keyaninan, yakni budaya konfusianisme dan agama leluhur. Sedangkan, inti pendidikan kewarganegaraan di Inggris berasal dari sejarah dan ideologinya.
\end{abstract}

Kata kunci: Pendidikan kewarganegaraan, Korea Selatan, Inggris

\begin{abstract}
Education is believed to play an essential role in advancing the nation's civilization. Almost every country instills citizenship through education in different ways. This difference is motivated by the development of history, economy, national identity, and culture of each country. This article aims to analyze citizenship education in South Korea and the United Kingdom by exploring the underlying attributes of the two countries. Both countries were chosen by similarity, which is to advance in the field of industry. The results of the study indicate that there are differences in the citizenship education curriculum in the two countries. The core of civic virtue education in South Korea comes from culture and keys, namely the culture of Confucianism and ancestral religion. Meanwhile, the core of citizenship education in England comes from its history and ideology.
\end{abstract}

Key words: Citizenship education, South Korea, United Kingdom 


\section{PENDAHULUAN}

Permasalahan paling fundamental yang terjadi di kawasan Asia Timur adalah permasalahan sejarah masa lalu yang melibatkan Cina, Jepang dan Korea Selatan. Hubungan historis ke-tiga negara tersebut sangat kelam, dimana Jepang tidak mau mengakui segala macam tindak kejahatan selama perang dunia ke-dua. Atas dasar itu, persaingan tiga negara ini sangat kompetitif di dunia internasional dalam segala bidang, khususnya bidang ekonomi. Berbeda dengan kawasan lain di Asia, kekuatan Asia Timur mampu mewarnai politik internasional dan mengimbangi kekuatan barat, menjadikan mereka berusaha untuk saling berebut pengaruh satu sama lainya (Purwanto, 2010).

Perkembangan-perkembagan negara yang telah dicapai tidak lepas dari kapabilitas sumber daya manusianya (Stewart, 2019). Kapabilitas tersebut terbentuk melalui sistem pendidikan. Sebagai contoh, Amerika memanfaatkan pendidikan untuk mengatasi masalah sosial dan China menggunakan pendidikan sebagai sarana untuk membentuk individu yang setia dan mendedikasikan dirinya untuk membangun masyarakat (Arif Rohman, 2010). Pendidikan di Korea Selatan juga memainkan peran penting dalam pengembangan masyarakat demokratis. Korea Selatan memanfaatkan sekolah untuk mempromosikan kesetiaan dan legitimasi kepada negara sambil mempromosikan nilai-nilai demokrasi liberal (Seth, 2012). Sedangkan di Inggris pendidikan tidak bisa lepas dari agenda politis (Kerr, 2003). Pendidikan ditujukan untuk meningkatkan literasi politik pemuda dan meningkatkan sikap demokratis (Weinberg \& Flinders, 2018).

Baik Korea Selatan maupun Inggris terkenal dengan tingkat kemajuan Industri yang cukup pesat. Inggris adalah negara industri tertua di Eropa dengan sektor industri yang cukup mapan. Berdasarkan data International Monetary Fund (IMF) outlook October 2018, GDP Inggris mencapai urutan ke-7 sedangkan Korea Selatan posisi ke-11 dari 50 negara yang diranking (http://statisticstimes.com). Walaupun Korea Selatan perekonomiannya masih di bawah Inggris namun sebagai salah satu dari empat Macan Asia Timur, Korea Selatan telah mencapai rekor pertumbuhan yang memukau. Data World Economic 
Outlook (April 2019) menujukkan pertumbuhan GDP Korea Selatan 2,6\% melampauai Inggris 1.2\% (www.imf.org/).

Pencapaian ini tentu tidak lepas dari partisipasi warga negara masingmasing. Jelas bahwa partisipasi warga merupakan perwujudan iklim demokrasi dalam rangka membangun negara (Bayeh, 2016). Beberapa negara mengakui bahwa warga yang loyal dan partisipatif dapat dibentuk melalui pendidikan kewarganegaraan (Seth 2012; Weinberg \& Flinders, 2018). Pendidikan kewarganegaraan memberikan pemahaman dan keterampilan anak untuk aktif terlibat dan bertanggungjawab dalam lingkungan politik, media, masyarakat sipil, ekonomi dan hukum (www.youngcitizens.org/). Oleh karenanya, Pendidikan Kewarganegaraan penting untuk setiap negara untuk mewujudkan warga yang positif, bertanggung jawab, dan mandiri (Enyiaka, Aminigo, \& Osaat, 2018).

Artikel ini bertujuan untuk membahas tentang pendikan kewarganegaraan dari negara Inggris dan Korea Selatan. Selain karena kedua negara memiliki pertumbuhan ekonomi yang cukup baik, kedua negara ini pernah mengalami pemerintahan berbentuk kerajaan, bedanya di Inggris kerajaan masih bertahan sampai sekarang sedangkan korea selatan sudah tidak. Segi kesebandingan ini yang menjadi dasar untuk mendeskripsikan bagaimana kerangkan pendidikan kewarganegaraan di kedua negara beserta latar belakang yang membentuknya.

Cummings (2001: 279) menunjukkan bahwa pendidikan kewarganegaraan di Asia erat kaitannya dengan penanaman kolektivisme. Contoh penerapan kolektif ini adalah adanya panduan hidup dalam kehidupan sehari-hari dan mendorong kesadaran sipil. Beberapa sikap yang ditanamkan di negara-negara Asia umumnya adalah mendorong apresiasi terhadap warisan budaya, penguatan identitas nasional, dan mendorong nilai kekeluargaan. Sedangkan bahasan tentang kewarganegaraan di Barat seputar hak dan tanggung jawab individu. Gagasan masyarakat sipil dibangun di atas pentingnya hak individu, yang membentuk dasar individualisme. Demokrasi juga didasarkan pada konsep hak asasi manusia dimana konsep kebebasan dikembangkan. Hak asasi manusia, hak individu, dan demokrasi adalah konsep penting dalam diskusi kewarganegaraan di Barat, dan hal ini berkontribusi pada konsep warga liberal (Heater, 1992). Individu 
merupakan basis analisis kewarganegaraan di Barat, baik mengacu pada bidang politik, ekonomi, maupun agama. Ada kecenderungan, ketika sebuah perbandingan antara Barat dan Timur dibuat, untuk menggambarkan Barat sebagai individualis dan Timur sebagai kolektivis.

Bahmuller (1996) menyatakan tentang citizenship/civic education di suatu negara bisa dilihat dengan menggunakan konsep atau teori perkembangan demokrasi. Ia mengungkapkannya bahwa perkembangan demokrasi tergantung pada sejumlah faktor yang menentukan, yakni: tingkat perkembangan ekonomi, aspek sosial politik, faktor yang ketiga yakni "civic culture and history". Perbedaan dua faktor terakhir bahwa aspek sosial politik mencakup identitas nasional yang berupa persatuan dan kesatuan bangsa, sedangkan "civic culture and history" mencakup aspek bahwa pengalaman sejarah dan budaya kewarganegaraan. Ketiganya menjadi landaaaasan penting bagi perkembangan demokrasi.

Konsep Bahmuller tersebut oleh Winataputra, U.S. (2017) dijadikan suatu pendekatan untuk memahami suatu negara bahwa untuk dapat memahami suatu negara dibutuhkan pendekatan lain yang secara langsung melihat kondisi suatu negara berdasarkan pendekatan tertentu. Pendekatan yang dimaksud adalah melihat sejarah suatu negara dari berbagai sudut pandang yang merupakan inti kehidupan bernegara. Menjelaskan bahwa untuk dapat memahami kondisi negara dapat dilakukan dengan menggali informasi berdasarkan empat hal, yakni perkembangan sejarah, perkembangan ekonomi, identitas nasional dan budaya kewarganegaraan. Dengan empat hal tersebut selain dapat digunakan untuk memahami civic education di suatu negara juga dapat digunakan untuk menganalisis perbandingan pendidikan kewarganegaraan di beberapa negara.

Dengan mempelajari dan membandingkan kedua negara industri tersebut akan diketahui bagaimana keadaban atau civic virtue dari masing-masing negara yang memiliki latar belakang sejarah, perkembangan ekonomi, identitas nasional, dan civic culture yang berbeda. Dengan demikian akan ditemukan pengalaman baik (best practice) yang dapat menjadi acuan atau bahan pembanding untuk negara-negara lain. 


\section{METODE}

Artikel ini merupakan hasil literature review tentang pendidikan kewarganegaraan di negara Korea Selatan dan Inggris. Kedua negara ini dipilih atas dasar kesamaan kesejarahan yaitu sama-sama negara yang memiliki intervensi kerajaan. Kedua negara tersebut juga masuk peringkat 20 dunia dalam bidang pembangunan ekonomi. Segi kesebandingan merupakan prasyarat sebelum mengomparasikan sistem pendidikan antar wilayah (Arif Rohman, 2013).

\section{HASIL DAN PEMBAHASAN}

\section{Civic Education di Korea Selatan}

Aspek kebudayaan Korea yang telah ada semenjak 4000 tahun yang lalu dengan dominasi ideology dan falsafat Confusius menjadi terancam dikarenakan silih bergantinya penguasa di Semenanjung Korea. Namun demikian, dengan berbagai gejolak politik dalam decade 60-70 an, Korea Selatan dapat tampil menjadi salah satu negara industry di Asia menyusul tetangganya Jepang. Pendidikannya juga telah berkembang sangat pesat walaupun cukup banyak tantangan untuk masa depan.

Menurut Frederich Harbison dan Charles A. Myers dalam Arifin, M. (2003) faktor-faktor yang mempengaruhi sistem pendidikan suatu negara secara tidak langsung adalah salah satunya faktor histori atau sejarah. Menurutnya fakor sejarah pertumbuhan masyarakat ditentukan oleh tiga hal yang saling berkaitan yaitu pendidikan, kemampuan manusia, dan pertumbuhan ekonomi.

Tipe budaya rakyat Korea berakar dari kepercayaan mistis (sihir) dan pemujaan pada nenek moyang, keduanya mempengaruhi kepercayaan Budha, Confusianisme dan Taoisme yang dikenalkan dari luar Korea, sehingga menurut faktor lain yang mempengaruhi pendidikan kewarganegaraan menurut Harbison dan Myers adalah faktor kehidupan agama. Agama yang dianut oleh masyarakat menduduki tempat penting dalam sistem kehidupan masyarakat. Setiap agama memiliki peran dalam mempengaruhi sistem kehidupan masyarakatnya. Selanjutnya adalah faktor kesukuan atau pengaruh rasialisme di beberapa negara 
terhadap sistem pendidikan. Kesemuanya menyatu secara harmonis dengan pemikiran tradisional dan budaya rakyat, budha dan konfusianisme berkembang pesat (Kementerian Pendidikan dan Pengembangan SDM Republik Korea 20072008). Hal tersebut juga mempengaruhi kebudayaan kewarganegaraannya. Budaya tradisional di Korea Selatan harus menyesuaikan dengan budaya modern karena efek negara industri, sehingga ada beberapa budaya tradisional yang hilang. Untuk mengembalikan yang hilang tersebut dan karena kepercayaan leluhur, menjunjung nilai-nilai luhur menjadi ciri khas dari negara ini, maka muncul pendidikan moral di Korea Selatan.

Dengan demikian kedudukan Pendidikan Kewarganegaraan di Korea Selatan terdapat dalam nomenklatur Pendidikan Moral, pendekatannya adalah ditetapkan sebagai inti terpadu dan spesifik (Winataputra, US, 2015). Landasan, konsep, kerangka sistemik, instrumentasi dan praksis civic education dapat dikaji dalam kurikulum pendidikan moralnya.

Menurut reformasi kurikulum nasional ketujuh di Korea Selatan (1997sekarang) dalam Young-Ran Roh (2004), pendidikan moral harus dilaksanakan oleh dua mata kuliah wajib dan tiga mata pelajaran pilihan. Diantaranya, subjek 'moral' diajarkan secara wajib di sekolah dasar, menengah dan atas dari kelas 3 sampai kelas 10 dan juga mengklarifikasi pendidikan kewarganegaraan yang demokratis sebagai satu dari empat sub-bidang utama (Kementerian Pendidikan Korea Selatan, 1999).

Ada empat fitur dasar yang menjadi bahan pokok 'moral' yang dirancang dalam Kurikulum Nasional ke-7 atau disebut Kurikulum Moral Ketujuh antara lain

1. Mengadopsi sebagai landasan teoritis untuk mengintegrasikan pendekatan etika kebajikan dan pendekatan kognitif. Pendekatan terpadu ini memengaruhi semua area kurikulum, yaitu, tujuan dan sasaran, konten, metode pengajaran dan pembelajaran, dan evaluasi.

2. Isi Kurikulum 'Moral' ke-7, mengikuti prinsip 'komunitas yang berkembang', terdiri dari 4 area kehidupan: Kehidupan Pribadi, Kehidupan di Keluarga, 
Lingkungan dan Sekolah, Kehidupan Sosial, dan Kehidupan Nasional dan Etnis.

3. Isi Kurikulum 'Moral' ke-7 mencoba menyelaraskan norma-norma moral dan nilai-nilai universal Korea namun memberi penekanan lebih besar pada yang pertama. Dengan demikian, ia mengadopsi sebagai tujuan pengasuhan warga Korea yang dibutuhkan daripada manusia yang diinginkan.

4. Kurikulum 'Moral' ke-7 menetapkan nilai/kebajikan inti dasar sebagai elemen pengajarannya, yang belum pernah dilakukan sampai Kurikulum ke-6. Ini memilih 20 nilai inti/kebajikan yang dianggap perlu untuk memimpin empat dimensi kehidupan (5 nilai inti/kebajikan, masing-masing untuk 4 area kehidupan). Buku teks baru disusun untuk menyampaikan nilai / kebajikan inti tersebut. 20 nilai inti / kebajikan adalah sebagai berikut: (1) Kehidupan Pribadi - menghormati kehidupan, ketulusan, kejujuran, kemandirian, kesederhanaan; (2) Kehidupan di Keluarga Lingkungan dan Sekolah kesalehan, tugas berbakti, etiket, kerja sama, cinta sekolah dan kampung halaman; (3) Kehidupan Sosial - taat hukum, peduli terhadap orang lain, perlindungan lingkungan, keadilan, menjaga rasa memiliki masyarakat; dan (4) Kehidupan Nasional dan Etnis - cinta untuk negara, cinta bangsa, kesadaran keamanan, penyatuan kembali damai, cinta kepada manusia.

Berdasarkan deskripsi diatas, terlihat bahwa pendidikan kewarganegaraan yang diselenggarakan Korea Selatan berkaitan dengan nilai kolektivisme. Siswa diajarkan untuk hidup sebagaimana mahkhul sosial yang berperan sebagai individu yang berperan dalam keluarga, lingkungan sosial, dan maupun warga negara dengan menjunjung nilai-nilai moral. Hasil ini selaras dengan yang disampaikan oleh Cummings (2001) bahwa pendidikan kewarganegaraan mendorong kesadaran sipil. Disamping itu, konsep pendidikan kewarganegaraan korea selatan merujuk pada konsep harmoni yang memuat pendidikan nilai. Konsep harmoni yang dimaksud di sini adalah nilai-nilai universal yang diperlukan untuk hidup sebagai warga negara yang bertujuan mengajarkan normanorma moral yang diinginkan untuk hidup dan sesuai dengan nilai-nilai pada zaman globalisasi seperti saat sekarang ini. Sehingga pendidikan 
kewarganegaraan menekankan pada penanaman konsep diri untuk mewujudkan hidup yang harmonis (Lee, 2004).

Namun, selama bertahun-tahun, pendidikan kewarganegaraan yang demokratis di sekolah-sekolah Korea telah dikritik karena gagal mengajarkan perilaku dan praktik demokrasi, dan hanya berkonsentrasi untuk menyampaikan pengetahuan atau mempromosikan pemahaman (Bae, 2000). Dengan demikian, salah satu tujuan pokok Moral dalam Kurikulum ke 7 adalah untuk menumbuhkan keterampilan berpikir moral dan penilaian moral, atau keterampilan yang diperlukan untuk memecahkan masalah moral yang diinginkan dan secara rasional dalam kehidupan sehari-hari (Ministry of Education korsel, 1999). Oleh karena itu, Kurikulum ke 7 mendorong guru untuk secara aktif mengenalkan metode investigasi dan diskusi yang berpusat pada siswa dalam praktik kelas mereka (Kementerian Pendidikan, 1999).

Cummings (2001: 279) menunjukkan bahwa pendidikan kewarganegaraan di Asia erat kaitannya dengan penanaman kolektivisme. Contoh penerapan kolektif ini adalah adanya panduan hidup dalam kehidupan sehari-hari dan mendorong kesadaran sipil.

\section{Civic Education di Inggris}

Sejarah Negara Inggris banyak diwarnai dengan perebutan kekuasaan dan konflik antarkerajaan serta perang saudara. Dari masa Romawi, dimana Romawi menginvasi Britania pada tahun 43 M pada masa pemerintahan Kaisar Claudius, dan wilayah itu selanjutnya dimasukkan ke dalam Kekaisaran Romawi dengan nama Provinsi Britania. Selanjutnya saat Romawi runtuh Britania diperintah oleh para pendatang yang kemudian juga terpecah menjadi beberapa suku, namun pada abad ke-7, suku-suku ini bergabung menjadi beberapa kerajaan seperti Northumbria, Mercia, Wessex, Anglia Timur, Essex, Kent dan Sussex. Kerajaankerajaan ini seiring berjalannya waktu saling menakhlukkan dan menguasai sampai Parlemen Inggris dan Parlemen Skotlandia sepakat untuk menggabungkan masing-masing kerajaan dalam sebuah kesatuan politik bernama Kerajaan Britania Raya (United Kingdom) pada tahun 1707. Untuk menegaskan "persatuan 
politik" tersebut, lembaga-lembaga seperti hukum dan gereja nasional di masingmasing kerajaan tetap terpisah.

Inggris semakin dewasa karena mampu menyelesaikan masalah pergantian dan perebutan kekuasaan yang terjadi berabad-abad tersebut. Hingga Negara ini menjadi negara industry besar di dunia setelah revolusi industry. Inggris pada dasarnya adalah sebuah negara industri. Namun, sejak tahun 1970-an terjadi penurunan dalam sektor-sektor industri berat dan manufacture, dan terjadi peningkatan dalam sektor industri jasa. Oleh karena perkebangan Inggris yang cukup baik dalam perekonomiannya, negara ini masuk kategori negara maju (Harbison dan Myers, dalam Arifin, M. (2003)

Selanjutnya identitas nasional suatu negara akan mempengaruhi budaya kewarganegaraan masyarakat negara tersebut. Istilah identitas nasional (national identity) berasal dari kata identitas dan nasional. Identitas (identity) secara harfiah berarti ciri-ciri, tanda-tanda atau jatidiri yang melekat pada seseorang atau sesuatu yang membedakannya dengan yang lain (ICCE, 2005: 23). Sedangkan kata nasional (national) merupakan identitas yang melekat pada kelompok-kelompok yang lebih besar yang diikat oleh kesamaan-kesamaan, baik fisik seperti budaya, agama, bahasa maupun non fisik seperti keinginan, cita-cita dan tujuan. Istilah identitas nasional atau identitas bangsa melahirkan tindakan kelompok (collective action yang diberi atribut nasional) yang diwujudkan dalam bentuk-bentuk organisasi atau pergerakan-pergerakan yang diberi atribut-atribut nasional (ICCE, 2005: 25). Identitas bangsa merupakan manifestasi dari nilai-nilai budaya yang tumbuh dan berkembang suatu bangsa yang membedakan dengan bangsa lain (Kaelan, 2007).

Identitas nasional di Inggris disampaikan Daniels bahwa, national identity is inflected by 'other forms of cultural-geographic identity, of region and locality'. If England's identity was seen to rest in the diversity of landscapes, cultures and regional identities, the Cotswolds could be identified as the 'best of England' because of, not in spite of, its apparent difference from other regions (Brace, C. 1999). Dalam pandangannya, identitas nasional dirubah oleh identitas budaya geografis, keyakinan, wilayah dan lokalitas lain. Oleh karena itu, pembentukan 
identitas budaya Inggris merupakan bentukan dari sejarah percampuran bangsa. Kebudayaan kewarganegaraan bukanlah kebudayaan modern tetapi salah satunya bagaimana mengkombinasikan antara kebudayaan modern dan tradisional (Gabriel A. Almond, 1989).

Pendidikan kewarganegaraan (citizenship eduation) di Inggris mulai mendapat perhatian yang sungguh-sungguh sebagai wahana pendidikan demokrasi pada 1997 yang terbit dalam dokumen yang dikenal dengan "white paper, excellence in School" yang mencanangkan komitment 'to strengthen education for citizenship and the teaching of democracy in schools'. Terbentuklah Advisory Group on Citizenship (AGC) dengan tugas untuk mengkaji dan memberi rekomendasi dalam rangka menyempurnakan kurikulum nasional yang pada tanggal 22 September 1998 berhasil menyelesaikan laporan akhir AGC dengan judul Education for Citizenship and the teaching of Democracy in Schools. Dokumen inilah yang kemudian dijadikan sebagai rujukan dan rambu-rambu pengembangan dan pelaksanaan citizenship education di Inggris (Winataputra, US, 2012).

Dalam dokumen tersebut (QCA 1998: 9) citizenship diartikan sebagai keterlibatann dalam kegiatan public oleh warganegara yang memiliki hak untuk itu, termasuk debat public dan secara langsung atau tidak langsung dalam pembuatan hukum dan keputusan negara. Namun, dalam konteks modern, warga negara itu adalah warna negara demokratis yang terdidik. Hal tersebut ditegaskan oleh QCA bahwa tidaklah mungkin dicapai suatu demokrasi Inggris yang sehat dan prospektif, kecuali dikembangkannya Inggris sebagai bangsa yang memiliki keterlibatan warga negara yang penuh. Oleh karena itu ditegaskan Pendidikan Kewarganegaraan haruslah menjadi pendidikan untuk membangun jatidiri kewarganegaraan dengan pusat perhatian pada pengembangan tanggung jawab sosial dan moral, perlibatan masyarakat dan kemelekpolitikan (Weinberg \& Flinders, 2018).

Tujuan Citizenship Education di Inggris menurut Winataputra U.S. (2012: 16) adalah pendidikan untuk kewarganegaraan, karena itu bukanlah hanya menekankan pada pengetahuan kewarganegaraan dan masyarakat kewargaan, 
tetapi juga pada pengembangan nilai, keterampilan dan pengertian. Hal tersebut dilatarbelakangi permasalahan di Inggris yang menemukan sebanyak 25\% dari warganegara berusia 18-24 tahun menyatakan tidak akan turut dalam pemilihan umum pada tahun 1992, dan meningkat menjadi $32 \%$ pada pemilihan umum tahun 1997 atau sekitar 55\%. Hal tersebut menunjukkan tingkat kemelkpolitikan dan partisipasi warga Negara usia muda sangat mengkhawatirkan perkembangan demokrasi Inggris ke depan. Oleh karenanya, Pendidikan Kewarganegaraan di Inggris penting untuk menanamkan hak individu dalam sistem demokrasi (Weinberg \& Flinders, 2018).

Pertimbangan dari AGC (QCA. 1998: 22-24) merekomendasikan: Citizenship Education (CE) menjadi elemen wajib kurikulum yang harus dipenuhi oleh semua sekolah. Hal tersebut diwujudkan sebagai hasil belajar untuk semua jenjang persekolahan dan bukan sebagai suatu program pengajaran atau mata pelajaran, learning outcome nya juga dirumuskan secara spesifik. Kemudian isi CE di tingkat perguruan tinggi mencakup pengetahuan, keterampilan dan nilai yang relevan pada budaya dan praktik demokrasi. Sedangkan waktu yang digunakan 5\% dari seluruh waktu yang digunakan di persekolahan. Selain itu sekolah-sekolah mempertimbangkan untuk melakukan kombinasi CE dengan sejarah dan mengkaitkan dengan keseluruhan isu-isu persekolahan. CE juga diterapkan di sekolah kejuruan. Pelaksanaan CE secara bertahap dan berkelanjutan. Seluruh unsur terlibat langsung dalam pendidikan anak, antara politisi, pelayanan masyarakat, wakil rakyat, organisasi keagamaan sampai guru dan orang tua siswa sendiri diberikan pengertian yang jelas tentang CE. Adannya komisi yang bertugas memonitor kemajuan dan bila perlu melakukan perubahan dalam pelaksanaan CE. Dengan demikian jatidiri "citizenship education" model Inggris yang di dalam perspektif internasional (Kerr, 1999) termasuk model "thick citizenship education" yang memiliki visi maksimum yakni "Education FOR Citizenship" dengan modus "across curriculum".

\section{Analisis Perbandingan dan Beberapa Penemuan}

Setelah diuraikan tentang latar belakang dan kurikulum pendidikan kewarganegaraan di dua negara yaitu Korea Selatan dan Inggris. Dari keempat 
fokus kajian terdapat beberapa perbedaan dan persamaan yang dirangkum pada tabel dibawah.

Tabel 1. Perbandingan Pendidikan Kewarganegaraan Korea Selatan dan Inggris

\begin{tabular}{|c|c|c|}
\hline \multirow{2}{*}{$\begin{array}{c}\text { Faktor yang } \\
\text { mempengaruhi } \\
\text { Pendidikan } \\
\text { Kewarganegaraan }\end{array}$} & \multicolumn{2}{|c|}{ Negara } \\
\hline & Korea Selatan & Inggris \\
\hline $\begin{array}{l}\text { Historical } \\
\text { Experience }\end{array}$ & $\begin{array}{l}\text { Bermula dari kerajaan yang } \\
\text { kemudian menjadi republic } \\
\text { Perang internal yaitu } \\
\text { konflik pecahnya wilayah) }\end{array}$ & $\begin{array}{l}\text { Terdiri dari kerajaan-kerajaan } \\
\text { yang kemudian terunifikasi } \\
\text { War (eksternal saat perang } \\
\text { dunia } 1 \text { dan } 2 \text { dan internal } \\
\text { berupa perebutan kekuasaan } \\
\text { kerajaan) }\end{array}$ \\
\hline $\begin{array}{c}\text { Economic } \\
\text { development }\end{array}$ & $\begin{array}{l}\text { Highly development } \\
\text { Negara industri }\end{array}$ & $\begin{array}{l}\text { Highly development } \\
\text { Negara industri }\end{array}$ \\
\hline National Identity & $\begin{array}{l}\text { Budaya Confusianisme dan } \\
\text { Taoisme. } \\
\text { Bentuk pemerintahan } \\
\text { republic dan menganut } \\
\text { demokrasi }\end{array}$ & $\begin{array}{l}\text { Monarki dengan sistem } \\
\text { parlementer, ideologinya } \\
\text { Sosialisme } \\
\text { Agama dominan Kristen, } \\
\text { terlihat dari benderanya } \\
\text { terdapat salib sebagai } \\
\text { pelindungnya. }\end{array}$ \\
\hline Civic Culture & $\begin{array}{l}\text { Bagi orang Korea, langit } \\
\text { adalah dasar bagi tatanan } \\
\text { moral dan landasan hidup } \\
\text { yang merasuk ke dalam } \\
\text { relung-relung kesadaran } \\
\text { umat manusia. }\end{array}$ & $\begin{array}{l}\text { Netralitas tetapi tidak } \\
\text { memisahkan negara dan } \\
\text { agama, setelah revolusi } \\
\text { perancis ikut mendengungkan } \\
\text { kebebasan, persamaan, dan } \\
\text { persaudaraan. }\end{array}$ \\
\hline Civic Education & $\begin{array}{l}\text { Pendidikan moral dengan } \\
\text { tujuan menumbuhkan } \\
\text { keterampilan berpikir dan } \\
\text { penilaian moral, atau } \\
\text { keterampilan yang } \\
\text { diperlukan untuk } \\
\text { memecahkan masalah } \\
\text { moral secara rasional } \\
\text { dalam kehidupan sehari- } \\
\text { hari. }\end{array}$ & $\begin{array}{l}\text { Education for Citizenship } \\
\text { dengan tujuan pendidikan } \\
\text { untuk kewarganegaraan, } \\
\text { bukan hanya menekankan } \\
\text { pada pengetahuan } \\
\text { kewarganegaraan dan } \\
\text { masyarakat kewargaan, tetapi } \\
\text { juga pengembangan nilai, } \\
\text { keterampilan dan pengertian. }\end{array}$ \\
\hline
\end{tabular}


Hasil diatas selaras dengan apa yang disampaikan oleh Kerr (1999) tentang konsep pendidikan kewarganegaran: pertama, pendidikan tentang kewarganegaraan yang berfokus untuk memberikan pengetahuan yang cukup tentang sejarah nasional, struktur, dan proses serta kehidupan politik pada pemerintahan. Kedua, pendidikan melalui kewarganegaraan mengajak siswa untuk terlibat langsung dengan melakukan kegiatan dan berpartisipasi aktif dalam pembelajaran disekolah. Ketiga, pendidikan kewarganegaraan yang dimaksud adalah membekali siswa dengan pengetahuan dan dilengkapi oleh instrumeninstrumen yang mendukung dalam pembelajaran seperti keterampilan, bakat, nilai-nilai, dan sikap atau disposisi yang ada di dalam diri siswa, yang memungkinkan mereka untuk berpartisipasi secara aktif dan bertanggung jawab dalam menghadapi kehidupan yang sesungguhnya.

Berdasarkan hasil analisis di Korea selatan, dapat disimpulkan bahwa negara tersebut telah mengadopsi konsep pendidikan kewarganegaraan di Asia dan yang dipaparkan oleh Kerr. Korea Selatan menerapkan pendidikan nilai dan moral dengan pendekatan terpisah yang menggunakan core keadabannya (civic virtue) yang berasal dari budaya dan religious. Budaya yang dimaksud yakni budaya konfusianisme dan keyakinan yang dimaksud adalah agama leluhur.

Sedangkan jatidiri "citizenship education" model UK yang menggunakan perspektif internasional (Kerr, 1999), termasuk model "thick citizenship education" yang memiliki visi maksimum yakni "Education FOR Citizenship" dengan modus "across curriculum". Pendidikan kewarganegaraan tidaklah secara khusus sebagai suatu mata pelajaran atau suatu topik, melainkan secara sistemik dimasukkan ke dalam keseluruhan tatanan kurikulum dengan memasukkannya ke dalam mata pelajaran yang ada (Winataputra, US. 2015: 67).

\section{SIMPULAN}

Pendidikan kewarganegaraan suatu negara ternyata bisa berbeda karena dipengaruhi oleh empat faktor berupa perkembangan sejarah, perkembangan ekonomi, identitas nasional dan budaya kewarganegaraan. Keempat hal tersebut berbeda di tiap negara, seperti di Korea Selatan dan Inggris. Berdasarkan hasil 
kajian dapat ditarik core atau inti dari pendidikan kewarganegaraan (civic virtue)pada kedua negara tersebut. Di Korea Selatan Civic virtue adalah berasal dari budaya dan religious, yakni budaya konfusianisme dan agama leluhur, sedangkan di Inggris core nya adalah sejarah dan ideologinya.

\section{DAFTAR PUSTAKA}

2015. Pendidikan Kewarganegaraan: Refleksi HistorisEpistemologis dan Rekonstruksi untuk Masa Depan. Tangerang: Universitas Terbuka.

Almond, G.A. and Verba, S., 2015. The civic culture: Political attitudes and democracy in five nations. Princeton University Press.

Arifin m. 2003. Ilmu Perbandingan Pendidikan. jakarta: golden Terayon Press

Bahmuller, C.E., 1996. The Future of democracy and Education for Democracy. Calabasas: CCE [Center for Civic Education].

Bayeh, E. (2016). Role of civics and ethical education for the development of democratic governance in Ethiopia: Achievements and challenges. Pacific Science Review B: Humanities and Social Sciences, 2(1), 31-36.

Brace, C., 1999. Finding England everywhere: regional identity and the construction of national identity, 1890-1940. Ecumene, 6(1), pp.90-109.

Dunn, Andrews \& Burton, Diana. (2011). New Labour, Communitarianism and Citizenship Education in England and Wales. Journal Education, Citizenship and Social Justice 6 (2) 169-179.

Enyiaka, J.U., Aminigo, I.M., Osaat, S.D. (2018). The Role Of Civic Education In Personality And National Development. International Journal of Social Science and Humanities Research. 6(1), 584-589.

Gou-Zeh, Y., 2006. Moral education in Korea. Journal of Moral Education, 8(2), pp.75-80.

International Monetary Fund. 2019. Real GDP Growth. https://www.imf.org/external/datamapper/NGDP_RPCH@WEO/O EMDC/ADVEC/WEOWORLD/GBR

Kaelan. 2007. Pendidikan Kewarganegaraan. Yogyakarta: Paradigma.

Kerr, D. (1999). Citizenship Education: An International Comparison. London: Qualiy Curriculum Association.

Lee, W.O., 2004. Concepts and issues of Asian citizenship: Spirituality, harmony and individuality. In Citizenship education in Asia and the Pacific (pp. 277-288). Springer Netherlands. 
Lee. W.O., \& Grossman, D.L. (Eds.). (2004). Citicizenship education in Asia and the Pacific Concepts and Issues. Hongkong : The University of Hong Kong Pokfulam.Ministry Of Education\&Human Resources Development. 2007-2008. Education in Korea. Republic of Korea

Michael Seth (2012) Education zeal, state control and citizenship in South Korea, Citizenship 28, DOI: $\underline{10.1080 / 13621025.2012 .651400}$

Roh, Yang.R., 2004. Values education in the global, information age in South Korea and Singapore.Citizenship Education in Asia and the Pacific: Concepts and Issues, 14, p.257.

Rohman, Arif. 2013. Pendidikan Komparatif Dasar-dasar Teori Perbandingan Pendidikan antar Negara. Yogyakarta: Aswaja Pressindo.

Statistic Times. 2019. Projected GDP Ranking (2019-2023). http://statisticstimes.com/economy/projected-world-gdpranking.php

Stewart, F. (2019). The Human Development Approach: An Overview. Oxford Development Studies, 47(2), 135-153.

Weinberg, J., \& Flinders, M. (2018). Learning for democracy: The politics and practice of citizenship education. British Educational Research Journal, 44(4), 573-592.

Winataputra. U.S. \& Budimansyah, D. 2012. Pendidikan Kewarganegaraan dalam Perspektif Internasional. Bandung: Widya Aksara Press.

Winataputra. U.S. 2001. Jati Diri Pendidikan Kewarganegaraan Sebagai Wahana Sistemik Pendidikan Demokrasi. Disertasi. Bandung: Pascasarjana PKn UPI.

Young Citizens. 2019. Importance of citizenship education. https://www.youngcitizens.org/importance-of-citizenshipeducation 